\title{
Meaning-Making Activity in the Emotional Experience of Borderline Personalities
}

\author{
Susi Ferrarello \\ Department of Philosophy \& Religious Studies, California State University, East Bay, Berkeley, CA, USA
}

\section{Keywords}

Emotions · Intersubjectivity · Phenomenology · Borderline personality disorder $\cdot$ Validity

\begin{abstract}
This article describes the mereological constitution of contents in the intentional acts of people affected by borderline personality disorder (BPD) or emotionally unstable personality disorder (EUPD) in order to shed light on the origin of the emotional instability characterizing this disorder. The article will first discuss the emotional cycle of people affected by this disorder; second, it will focus on the mereological aspect of the meaning-making ${ }^{1}$ experience in the intentional act; third, it will show how this meaning-making experience usually interacts with axiological ${ }^{2}$ qualities that affect the continuity of their sense of reality. From the investigation, it emerges that the mereological constitution of contents occurs in a way that is disruptive of the continuity of BPD/EUP$\mathrm{Ds}^{\prime}$ interaffective lifeworld as it generates intersubjective disturbances on the axiological, logical, and ontological levels. On this basis, as a concluding suggestion, the paper will propose an alternative way to approach the problem, soothe the disturbance, and encourage integration.
\end{abstract}

(c) 2021 S. Karger AG, Basel

\section{Introduction}

How can emotions take over reality? How does it happen that an emotional reaction has the power to cloud one's personal judgment? What can we do to harmonize meanings and emotions?

The article will answer these questions through a phenomenological description of the mereological constitution of contents in the intentional acts of people affected by borderline personality disorder (BPD) or emotionally unstable personality disorder (EUPD). The continuity of the affective resonance ${ }^{3}$ of their interaffective ${ }^{4}$ lifeworld $^{5}$

\footnotetext{
What meaning-making, sense-making, meaning in life etc. can indicate varies, especially across all psy- and phil-disciplines (including psychiatry, psychology, psychopathology, psychoanalysis, cognitive psychology, the philosophy of mind and so on). For this reason, here follows a literature that can serve as a starting point to clarify the intricacy of these expressions [42-60].

2 In the text I will write "axiological" in a hyphened and not hyphened way. I use this latter when I need to refer to the value quality proper to this adjective. The former hyphened version helps me to express its intrinsic combination with the meaning/logical components that bring its value content to expression.

3 I define affective resonance as "the capacity to share or become affectively aroused by others" emotions" [40, 41].
} 
might become severely disrupted by the way in which general meanings (abstracta) are constituted in the ontological foundation. To use an example, a BPD/EUPD might feel the most loved person in its own family in a moment and the outcast of the same family the moment after because of the way in which its mother replied to a question or even just out of an intruding memory that crossed its own mind. The interaffective and intersubjective world of BPD/EUPDs is populated by characters that come and go as quickly as BPD/EUPDs' emotions. What I am going to discuss in the paper is that, to my understanding, this disorder is about their interaffective world and its disturbances. In fact, the emotional components of the sensuous apprehension of meaning seem to hold an axiological property that has the power to overrule its logical ${ }^{6}$ components, thus affecting the intersubjective interactions of everyday life. Scheler [1] would call this an ordo amoris disorder, because on the one hand, this axiological property affects the way in which the individual's emotion structures its internal reality and its intolerance of negative values associated with other people. On the other hand, the structure of social and intersubjective relationships triggers a value perception of other people that is very disruptive for the continuity of BPD/EUPDs' interaffective lifeworld. Since in the paper I use a mereological approach, my explanatory direction of the disor-

\footnotetext{
4 I use interaffectivity henceforth in this sense "interaffectivity is regarded as an intertwinement of two cycles of embodied affectivity, thus continuously modifying each partner's affective affordances and bodily resonance" [35, 61]. "Interaffectivity includes body feedback (i.e., the impression function within self and other) which is necessary for interbodily resonance. Components of interbodily resonance are: mirroring or complementing movements, body awareness (via proprioceptive body feedback), and kinaesthetic empathy; they are psychotherapeutically important in phenomena such as somatic countertransference" [62].

5 For this concept I draw completely on Husserl's writings. In his Crisis (1936) he writes: "In whatever way we may be conscious of the world as universal horizon, as coherent universe of existing objects, we, each "I-theman" and all of us together, belong to the world as living with one another in the world; and the world is our world, valid for our consciousness as existing precisely through this "living together." We, as living in wakeful worldconsciousness, are constantly active on the basis of our passive having of the world... Obviously this is true not only for me, the individual ego; rather we, in living together, have the world pre-given in this together, belong, the world as world for all, pre-given with this ontic meaning... The we-subjectivity... [is] constantly functioning" [63, p. 108-9]

6 Here I will use the term logical in the same way as Husserl used it in his Logical Investigations as a term closer to epistemology than symbolic logic.

From now on these two directions will be referred as (A) and (B) in the paper. These two vectors are also indicated in the figure.

From here on I refer to Borderline Personality Disorder or Emotional Unstable Personality Disorders with these acronyms.

9 While the psychodynamic approach to BPD/EUPD has plenty of merits, for the goal of this paper I will refer to BPD/EUPD's descriptions as they appear in the diagnostic manuals, DSM V and ICD X.
}

der will go from the affective disorder to the structure of social experience (A) and from the impact that the structure of the social experience exerts on the emotional disorder $(\mathrm{B})^{7}$.

Hence, the article will first discuss the emotional cycle of people affected by this disorder; second, it will focus on the mereological foundation of the meaning from its ontological and categorial perspective; third, it will show how this meaning-making experience usually interacts with axiological qualities that affect the continuity of their sense of reality. The overall goal of the paper is to focus on one of the many elements that contribute to the disturbance of intersubjectivity experienced by these individuals so that clinicians and caregivers can find alternative ways to approach the problem, soothe the disturbance, and encourage integration.

\section{More Care Is Needed}

BPD/EUPDs' life seems to be marked by a constant struggle to regulate emotions; these individuals tend to engage in impulsive and self-damaging behaviors, often leading to stormy and unstable interpersonal relationships $[2]^{8}$. Despite the cost that this disorder has on both the health-care system $[3,4]$ and the personal, economic, and societal finances [5], a certain resistance is encountered from clinicians who work with these clients due to the high-risk behavior that they represent for themselves and others [6]. As a result, social networks are less willing to provide support for these individuals to learn how to cope with distress, further impairing their emotional regulation abilities [7]. Understanding the structure of the emotional dysfunction that is behind this disorder can be beneficial to both BPD/EUPDs and the clinicians working with them.

Phenomenological literature on the problem [8-10] agrees to interpret any symptom associated with this disorder as a way to understand their lifeworld [11]. I believe that these symptoms could be investigated as a consequence of the disruption of the interaffective lifeworld. The symptoms mentioned above are, in fact, a logical consequence of the affective disturbance in the resonance that should keep BPD/EUPDs connected to their intersubjective and interaffective community. In accordance with Mancini and Stanghellini [11], I think that the emotional cascade of problems such as alexithymia, hypersensitivity, and the empathy paradox ${ }^{9}$ affecting BPD/EUPDs' life can find logical explanations if we access their interaffective lifeworld. 
How Does This Problem Arise? What Are the Consequences?

In BPD/EUPDs' emotional development, their intersubjective and interaffective demands are not duly met during their early development. Biosocial theory [12] stresses the poor social functioning of the environmental answers toward the emotional vulnerability of the developing child. The child's biologically based emotional vulnerability is handled in a way that is perceived as invalidating, minimizing, or trivializing. From this, it follows impulsivity, poor social functioning, emotional sensitivity, and reactivity, a slow return to baseline [12], sadness, hostility, and fear [13]. Some scholars believe that these aspects are due to large-scale cognitive deficits $[14,15]$ that extend, at times, to affective decision-making processes. BPD/EUPDs, for example, tend to make significantly more disadvantageous decisions concerning delay-discounting tasks, wanting immediate rewards over long-term gain $[16,17]$, discounting rewards that were less certain [17], or with problems that involve potential losses [18]. Laboratory studies showed how the high emotional reactivity is often characterized by shame [19], anger [20], and fear/anxiety [6] and accompanied by greater amygdala reactivity [21]. BPD/EUPDs might tend to perceive negative evaluations or criticism from others in a darker light than how they were originally meant $[22,23]$ or to misinterpret positive cues in a negative way, thus often feeling rejected [24, 25].

The most common response to the perceived rejection is rumination $[26,27]$ which can be defined as a repetitive, unproductive thought. Rumination, generally, leads to that "emotional cascades" [27], in which distress is amplified and discharged in impulsive attempts to escape emotions. Hence, rumination resonates with anger [28], shame [29], lower levels of engaging in present-focused awareness [30], and difficulties with handling intense emotional arousal [31].

\section{First-Person Lived Experience}

Narratives from BPD/EUPDs' first-person lived experience seem to confirm the traits discussed above. Here, for example, Jill writes: "I know I keep having these ups and downs, but if I don't get off this roller coaster, I'm worried he's just going to get sick of it and leave me" [32].

Emotional reactivity and instability impact BPD/EUPDs' romantic relationships in a very negative way. In fact, the instability of their interaffective lifeworld impairs their sense of belongingness so necessary to a healthy personal and social life. It is as if constant interferences threaten them to exclude themselves from their own life- world at any moment. To add to this, these threats are often not empty. In fact, even though BPD/EUPDs' lives might be filled with important people, the instability of their emotional life puts such a strain on their interaffective bond that it is always difficult to predict how long a meaningful relationship will last. This triggers, of course, a vicious circle that increases BPD/EUPDs' emotional reactivity. In another passage, Natasha writes: "I had always felt 'different' growing up. I didn't have a stop button when it came to regulating my emotions. Even the 'good' emotions, exhausted me."10

Emotional reactivity is often disempowering. Being emotionally very reactive might lead to not feeling in charge of one's emotional choices. The intensity of their reactions is such that it takes away important decisional power off their hands and often drains their energy through this ongoing flow. These individuals end up feeling exhausted even if from an external point of view their life seemingly goes easy and safe. On this point, Natasha continues: "Over the years I've heard people say the following statements to me, repeatedly"; "You're getting obsessed again!" "You're so sensitive!" "Stop overthinking and analyzing everything!" "You're so weird." "You were really inappropriate last night." "You are too intense." "You are too much." "You are so over the top."

Perceiving a qualitative difference between oneself and others generates a sense of stigma that prevents a healthy constitution of interaffective community. The resonance between oneself and others gets lost in the emotional reactivity and with it the major risk is to lose the sense of oneself as a part of one's own lifeworld. As a consequence, a sense of isolation and shame initiates even more selfharming feelings and rumination thoughts.

An implied obligation to be different and happier is felt as an underlying condition to be part of the social intersubjective context. Complying with that obligation would solve their feeling of loneliness, but yet it would be too difficult to fulfill because it would mean to betray their intimate nature. So, Jesse writes: "I was told to 'stop wasting people's time' and I was 'being a burden and impacting my friends too much.' They even said that I shouldn't be so unhappy because my family always went on nice holidays. I was regarded as being 'too difficult to deal with' which didn't correlate with how I had been seen previously. When it wasn't an easy fix, they thought I wasn't trying to help myself and were frustrated."

10 Although there is a wide phenomenological literature on these issues, for reasons of space I will address only these first two problems as a consequence of this disorder from a strictly Husserlian perspective. 
The most logical behavior that follows from this implied obligation is self-exclusion. This means that instead of trying to fit in, the subject prefers quitting the relationship before being formally excluded from it; in this way, the stress and anxiety accompanying the impending sense of exclusion is won by the relief gained in knowing that the anticipated emotional pain generated by the actual exclusion will be avoided ${ }^{11}$. It happens often that when the individual feels that it is about to be excluded from its intimate or social circle, the first reaction is not rage but self-exclusion and the creation of an alternate paler reality where to live [29]. Paradoxically, the trauma excluded themselves from the affective circle of their family, society, friends, and personal intimacy. Now they exclude themselves from their own intimate life and, accordingly, from a beneficial connection with their emotional and geographical environment. The problem with BPD/EUPDs' way of interpreting social cues is such that the selfexclusion might occur before any intention of exclusion is conceived in their intimate circle. Hence, they exclude themselves before their intimate ones can understand why. Their own intimate self remains as a witness but in the form of a stranger that looks at that life as if from an external point of view: "My feelings were completely dismissed, and I was told that 'I hadn't experienced any trauma so I shouldn't be struggling.' I had no explanation for how I was feeling so it became internalized."

Jesse did not go through any trauma; her family was good and wealthy. Hence, the implied obligation to which Jesse felt she should have complied was to be happy in order to feel part of her interaffective world. Even though this implied social conditioning might have stemmed from Jesse's rumination or misleading emotional perception, we have seen above how social and clinical structures are still very lacking in relation to the support they can provide for this emotional disorder; hence, it is very likely that what was perceived by Jesse (and many more BPD/EUPDs) meets, to a certain extent, an implied social demand. Probably, Jesse perceived something that was actually justified by the behavior of the people around her. In another testimony, a participant writes: "Before my diagnosis I was so confused as to why I felt the things I did, and so I breathed a sigh of relief when my psychiatrist spoke about EUPD to me as it all just made so much

11 This and the following excerpts are retrieved from a website devoted to preventing mental health discrimination. In this forum people suffering from this problem felt free to share their experience about their diagnosis and their life before then: https://www.time-to-change.org.uk/blog/unhelpful-attitudes-made-me-feel-isolated. sense. EUPD is exhausting and I feel like my mind is on overdrive 24/7. When struggling to explain myself to others, I was told that this was all a made-up thing in my head and that I shouldn't be trusted, because if I could make something like this up then what else would I be making up?"

Being diagnosed might represent for some a way to feel seen and accepted in their intersubjective and interaffective world although more work needs to be done in phenomenology and descriptive sciences, in general, to find an inclusive and descriptive language for BPD/EUPDs' lifeworld to be acknowledged. This intersubjective language would contribute to the creation of more space within which one can develop a sense of belongingness. Being emotionally exhausted and living on a different emotional wavelength than the people around them makes it extremely difficult to explain one's self in a clear manner and feel part of the same community. Yet, if the intersubjective language of science finds its way to the larger society, this can facilitate an intersubjective dialogue and initiate an easier approach to regain a sense of more stable belongingness. An attempt in this direction can be represented by the description of the logic behind BPD/EUPDs' choices.

\section{BPD/EUPDs' Logic}

To this purpose, Mancini and Stanghellini [11] individuated three forms of logic stemming from three specific values on which BPD/EUPDs' constitution of lifeworld seems to be based (A): (1) the logic of intimacy whose main value is belongingness and mutual recognition; (2) the logic of spontaneity whose value is authenticity; and (3) the logic of instantaneity whose guiding value is intensity. The ordo amoris around which BPD/EUPDs constitute their sense of reality is invested in this "visceral need of belonging, being accepted and loved" and their guiding principle of actions are commanded by "the intensity of emotional values which are nevertheless constantly frustrated by the ethical norms and the social rules and conventions that structure their shared interpersonal world" [11]. Any attempt to sooth emotion and procrastinate decisions takes something away from the immediacy with which this normative intensity needs to be expressed. These logics are an active component of the axiological way in which BPD/EUPDs constitute the reality of their lifeworld and are at the origin of the disturbance of the interaffective resonance of BPD/EUPDs' lifeworld. In fact, BPD/EUPDs' lifeworld seems to be quite frightening and exhausting since the continuity of its affective structure comes and goes as easily as their emotions do. Ac- 
cording to these logics and their core values, not only the love of their parents but even their very affective existence can disappear at the same speed as their emotions. Here, of course, I do not mean to say that they actually think that their parents would no longer exist if negative (or positive) emotions occur in relation to them; what I am saying is that their parents would stop resonating with them and accordingly BPD/EUPDs would exclude them from their sphere of belongingness. The rollercoaster they live is not only about emotions but is about existence and nonexistence; the loved ones populating their interaffective lifeworld would alternatively cease to exist for them or to be there for them according to the emotional resonance of the moment. In fact, the value attributed to a smile when expected or to a phone call that was not answered has the power to disrupt their sense of belongingness to their affective lifeworld. This disruption is connected to a general axio-logical instability.

The instability characterizing BPD/EUPDs' constitution of values and logic simply mirrors the instability of their lifeworld. In what follows, I will show how the existential outcome of the axiological instantiation in the meaning-making experience of BPD/EUPD can generate the disruption in the affective resonance that connects these individuals to their intersubjective and interaffective world (A) and how the structure of this intersubjective and interaffective world can trigger the disruption (B). BPD/EUPDs feel detached from their social environment and pressured to be different, leaving persons so afflicted in a dilemma, and unable to enter into a fulfilling interaffective resonance. Shedding light on the axio-logical steps that lead to the constitution of meanings can help to understand where to intervene to sooth this blockage.

\section{The Mereology of Meaning-Making Experience}

Let us come back to the questions I raised in the introduction: How does the experience of being in the world come together in our minds? How does it happen that the world becomes the content of our lived experience? How do we act upon the content of our lived experience in our daily life? Mereology can help us to answer these questions and to elucidate further the problem that arises in the emotional dysregulation of BPD/EUPDs. The term mereology was coined in 1927 by Leśniewski ${ }^{12}$ from

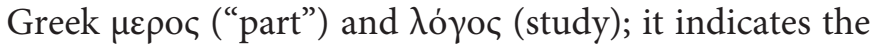
study of parthood relations with the goal of describing the relations of parts to the whole and the relations of part to part within a whole - in this case, the whole is represented by the content of the acts that animate one's lived experience. Even though the term is fairly new, its roots date back to antiquity ${ }^{13}$. Here, I use Husserl's mereology [33] to illustrate the explanatory direction of the meaningmaking process (A) and (B) and its disturbance in $\mathrm{BPD} /$ EUPDs' value perception.

According to Husserl [33], independent objects can be concreta, which might become whole on their own if separated from the whole - for example, the leg of a table. Nonindependent objects (abstracta) are relative to the whole of which they are part - the green of the grass [34]. Husserl mentions two forms of foundation: categorial (from abstractum) and ontological (from concretum). In the first one (A), from abstractum, the categorial act founds sensuous data ontologically [34, p. 235]. For example, in order for us to call the students of a school "students," we need to ascertain that these children attend a school. In this kind of foundation, the abstractum (categorial), that is, the epistemological category school ontologically founds the quality of the children who are not only children but also students.

In the second one, the ontological, the foundation moves from the concretum to the abstractum (B). For example, I need these living beings, the students, in order to acknowledge the existence of a school, citizens to acknowledge a government, athletes for the Olympics; without these ontological instances, a school would be just an anonymous building.

This latter form of foundation of meanings, which affects the logic of BPD/EUPDs, is problematic because the concrete existence for them comes and goes according to the axio-logical component accompanying the value apprehension (regardless of their being positive or negative). BPD/EUPDs' value perception does not always arrive to completion in the ontological foundation; that is, the concreteness of being cannot fully instantiate itself in the abstractum to produce general meanings. To use an example from a common lived experience, the meaning value "friend" that a BPD/EUPD would attribute to the concreteness of a specific living being resonating with

\footnotetext{
12 I wrote more on the paradox of self-exclusion in [64].

13 In literature, "mereology" is also devoted to the study of a system decomposition as in General Systems Theory. It is not until Leśniewski's Foundations of the General Theory of Sets (1916) and his Foundations of Mathematics (1927-1931) [65] that we arrive at a general formulation of the theory of part-relations; yet, since Leśniewski's work was largely inaccessible to nonspeakers of Polish, we have to wait until the publication of Leonard and Goodman's The Calculus of Individuals (1940), partly under the influence of Whitehead, to read about mereology as matter of interest for modern ontologists and metaphysicians.
}

Meaning-Making Activity in the Emotional Experience of Borderline Personalities
Psychopathology 2021;54:221-231

DOI: $10.1159 / 000517932$ 
Fig. 1. Mereological foundation. Concretum and abstractum point to a twofold explanatory direction of the meaning-making process. From abstractum to concretum (A) and from concretum to abstractum (B), the meaning is founded in a categorial form of existence, existence as sense, that is, school (-logical), and in an ontological way as existence for (axio-), that is, the student. The axio-logical disruption generates an unknown or hole in the texture of existence (X) that is perceived as emptiness. On the side of the categorial foundation, this $\mathrm{X}$ generates the interaffective disturbance, and on the side of the ontological foundation, this disruption is self-medicated by numbing activity.



their interaffective lifeworld is not fully acknowledged but it might remain an un-categorized affective necessity if a negative value accompanies the apprehension of that concreteness. The concreteness of a friend who is not smiling back or did not pick up the phone at the right time does not become an existence for the BPD/EUPD because it is disturbed by the value apprehension. Hence, a sense of emptiness prevails over the logical or categorial side of the instantiation because moments of that concreteness are not seen as existent for them. To this, BPD/EUPDs react with numbing activities [9] that try to silence - with little if no success at all - the concerns arising from the missing moments of the ontological foundation; instead of producing informative value meanings (axio-logical content), these activities generate new concerns and inner torment (see Fig. 1). On the logical or categorial side of the foundation what remains is an interaffective disturbance characterized by a general sense of missing out. This lived experience could be compared to the sense of missing out that a foreigner can experience when using a

14 The roots of mereology in antiquity can be traced back to the Presocratics and continuing throughout the writings of Plato (especially the Parmenides and the Theaetetus), Aristotle (especially the Metaphysics, but also the Physics, the Topics, and De partibus animalium), and Boethius (especially De Divisione and In Ciceronis Topica). Mereology occupies a prominent role also in the writings of medieval ontologists and scholastic philosophers such as Garland the Computist, Peter Abelard, Thomas Aquinas, Raymond Lull, John Duns Scotus, Walter Burley, William of Ockham, and Jean Buridan, as well as in Jungius's Logica Hamburgensis (1638), Leibniz's Dissertatio de arte combinatoria (1666) and Monadology (1714), and Kant's early writings (the Gedanken of 1747 and the Monadologia physica of 1756).

15 In his Ecology of the Brain, Fuchs [67] proposes a similar mereological model to illustrate the way in which the experience behavior induces changes in the neuro-plasticity of our brain which, on turn, modifies the dispositions with which we behave in our experience. new language: an interlocutor engaging with them in the conversation might use words or sounds that are difficult to grasp. These unidentified sounds create little holes of sense that makes it very demanding for the foreigner to reconstruct the general meaning of what has been said ${ }^{14}$.

The interaffective world of BPD/EUPDs cannot always count on the existence of general intersubjective categories, such as friends, family, and relationships. This happens because the emotional quality of the concreta is so axiologically pervasive that can cloud the ontological presence of these categories, accordingly impeding a foundation of meaning that makes intersubjectively sense. In this way, BPD/EUPDs miss the abstracta, the universal categories in which we all find refuge to understand each other and build our Mitwelt. A clinical approach could intervene on stressing the importance of intersubjective - and not solely subjective - meanings ( $a b$ stracta) to avoid that their interaffective world becomes impoverished as a consequence of axio-logical misleading interpretations toward self-exclusion (for more on this interpretation, see the section Consequences of the Mereology in Meaning-Making Experience in BPD: A Blind Motivational Affective Necessity). Concreta and abstracta point to two different ways of existence, the existence for (axio-) $)^{15}$ the subject and existence as sense (-logical); together they bring sense (Sinn) to our life. Disturbed value perceptions generate little "holes of existence" that should knit together the complex texture of life. This results in a sense of emptiness that is self-medicated by numbing activities (drinking, compulsive expenditures, etc.) [9]. The sense of emptiness would come from the mismatched correlation between categories of meanings and ontological concreteness because this latter 
remains an unknown whose value qualities need to be further characterized. What is often left is an empty categorial meaning whose meaning existence is no longer nourished by "the existence for"; hence it does not provide the sense ( $\operatorname{Sinn}$ ) that one would need to feel belongingness and continuity to one's own interaffective lifeworld (family, work team, romantic relationship, etc.). If anything, this empty category of meaning (abstracta) expands the sense of emptiness in their interaffective life because it is an ontologically ungrounded affective necessity (see Fig. 1).

\section{The Role of Axiological Acts in the Meaning-Making} Experience of BPD/EUPDs

The ontological foundation of meaning ( $\operatorname{Sinn}$ ) for $\mathrm{BPD} / \mathrm{EUPDs}$ ' lived experiences seems to be made unstable because of the existential interference that axiological acts exert on the concreta within the foundational act of abstracta. Originally, something has value because it exists [34 $]^{16}$ and manifests its "there-ness" for us as a necessity that converts the concreta to prominence, that is, into units acknowledged as wholes or general meanings (e.g., family). In BPD/EUPDs' affective lifeworld, the family, as a meaning, which has a very specific intersubjective and social function, has an intermittent existence for their interaffective world and its existential reality ${ }^{17}$. "You have never been there from me" is the typical sentence stemming from this value apprehension and its logic.

What happens in BPD/EUPDs is that the affective necessity that should bring to expression the good value (Gutwert) or existence value (Daseinswert) [34] often turns blind or, at best, colors in dark tones these concreta, thus clouding or even preventing their being to become prominent and there for their lifeworld ${ }^{18}$. Let us use an example: a father has two grown-up daughters who live half an hour away from him. One of the two drops by his home to give him something that he had lent her weeks ago. Time goes by, they start talking and have a coffee together. The other daughter, the BPD one, casually stops by, too, that day. As she enters the house, she sees the two

\footnotetext{
16 What Husserl would call (wertvoller Leistung) [35, p. 137-143]

17 Daseinswert (existential value) is the term that Husserl uses to refer to the primordial "axiological functioning" (wertvoller leistungen) [35, p. 137-143] with which the primordial value of "being there" is brought to light.

18 Normally, converting the concreta to prominence produces a Wertsein (being-value), a unit whose worth comes exactly from the fact that its concrete blurred components come into being as a perceivable prominent unit among other beings. Hence, the Daseinswert is an axiological core that, in its there-ness for or wertvoller Leistung, calls for the constitution of other prominent units that transform the concreteness of experience into personal meanings.
}

Meaning-Making Activity in the Emotional Experience of Borderline Personalities of them together amiably having a coffee and sharing talks. The value apprehension of this scene could trigger a strong sense of exclusion and interrupt the interaffective resonance she has with them. Such encounter can compromise the meaning that their existences have in her interaffective lifeworld. Even if her father and sister are still the same persons, in the BPD/EUPDs' interaffective lifeworld, their being-there-for her in her lifeworld would cease to exist. Their existence as father and sister for her would be disturbed and no longer have a meaningful place for that moment.

In BPD/EUPDs' interaffective lifeworld, it happens that her sister and her father will no longer be/exist/be prominent, in the sense of being-there-for-their-lifeworld, if the axiological instantiation of its meaning is perceived as a negative one. They can literally disappear from their interaffective lifeworld, and accordingly, their non-presence for them can be perceived as a threat to exclusion, which would prompt, in turn, the self-excluding behavior I described above. The ontological concreteness does still exist but not as a part of their interaffective world; the universal categories of inclusiveness come and go according to the negative value attached to their concreteness. The existence of BPD/EUPDs' affective lifeworld is significantly unstable because of this defect in the mereological constitution of meaning caused by a somewhat blind affective necessity that does not bring to prominence concreteness negatively charged. BPD/ EUPDs might become literally emotionally incapable to resonate with her sister and father's being and be surprised by the fullness of their life. This does not mean that $\mathrm{BPD} / \mathrm{EUPD}$ are capable of ignoring persons associated with negative values as if in their minds these persons have ceased to exist. Quite the opposite, their non-presence becomes more and more prominent. According to the pattern I described above, they wish to numb the nonpresence but its volume, in fact, grows. The unacknowledged concreteness represents a loud disturbance of the continuity of interaffective meaning within their lifeworld. The fact that the person is not there for their affective lifeworld becomes an emotional and a logical weight. This absence disturbs the harmony of their inner world and triggers an intense sense of abandonment and longing for wholeness. The axiological quality of any prominence is prompted by an affective necessity that might prevent this concreteness from becoming a general meaning that exists there for me. Helping BPD/EUPDs to connect with this affective necessity and the correlated constitution of meaning can be a way to soften the potential disruption of the axiological acts. 
The axiological aspect of any meaning has an existential strength that impacts the continuity of the ontological foundation of the meanings that populate their interaffective world, which becomes bigger and smaller according to the tide of this axiological instability. In a healthy life, coming to prominence is always good independent of the actual quality of a person as a human being ${ }^{19}$. "I see my father. My father's being there for my lifeworld is good," in BPD/EUPDs' interaffective lifeworld, this might become "I see my father. My father is having a coffee with my sister and he did not invite me. My father's being there for my lifeworld is not good. He is a threat for my world." Any resonance at this point is impossible. For this reason, $\mathrm{BPD} / \mathrm{EUPD}$ might experience an existential form of loneliness and isolation because the potential concreteness of the "characters" populating their lifeworld might not come to prominence as they might be repeatedly recognized as invalid. The axiological quality with which her father and sister come to existence and brings its matter to existence for her is recognized alternatively as good (i.e., worthy to be) for her lifeworld and bad (i.e., not worthy to be) for her lifeworld. It is as if BPD/EUPDs' interaffective world sounds like a radio whose frequencies are always making disturbing noises and do not let them relax and just enjoy the melody of the song. As Schmidt [9, p. 214] writes: "Often, persons with BPD feel that there is no remedy to kill the emotional pain other than to numb themselves, for example, via substance abuse and/or by adopting a detached attitude toward everyone and everything that appears to be a cause of the pain." The disturbing noises grow louder and louder as the full melody becomes more difficult to be grasped. Ignoring the noise as much as cutting with the disturbing relationship would not bring any relief because that missing frequency presents a hole of meaning that interrupts the continuity of sense in their life. For this reason, the disturbing frequencies are not just disturbing, but they represent an existential threat to their integrity. These missing moments increase their sense of emptiness and numbness as they actually swallow meanings from within their interaffective life. In that sense, the clinician can provide support in helping them to develop higher awareness of the value perception with which they bring to prominence even the simplest categorial contents so that if an interaffective disturbance occurs, it is not too disruptive of the continuity of their lifeworld.

19 For reason of space, in this article I focused on negative example but the same is for the opposite case in which positive-value apprehension would prompt very quick additions to their inter-affective life-world.
Consequences of the Mereology in Meaning-Making

Experience in BPD: A Blind Motivational Affective

Necessity

As Staiti [36, p. 63] remarks, "in phenomenology, intuition represents the apex of an experiential process, that is, the congruence between the sense as it is thought and the sense as it has been actually experienced". How this congruence comes together in the intentional content is explained through the notion of mereological foundation. As showed above, foundation describes a mereological relationship of parts and whole in which a complex experience and its object can be analyzed according to their mutual inferences.

In BPD/EUPDs, this sense of wholeness and connectedness to the parts is not so easy to achieve since the concreteness of the intentional content is mostly shaped by axio-logical acts in a biased intermittent way. The position taking proper to the emotional acts needs a logical layer for the emotional content matter to be brought to the fore. If this layer is missing, what remains is a blind motivational affective necessity that moves the need to belong to a family toward its object of love but without being able to express its being in words or being aware of their existential concreteness. When the concreteness of the ontological foundation is undermined by a lacking categorial foundation (A), the inevitable result is to feel left with a frustrating sense of necessity whose axiological interpretation often assumes negative tones and even denies the being of this matter.

Axiological properties in general, like those that characterize emotional acts, need objectivating predicative acts to bring that motivating/-ed matter to the fore ("I feel something for my family I cannot explain"). Values need predicates as much as axiology needs logic (and vice versa) in order to be expressed to its fullest epistemological and ontological way. The intentional essence of the emotional content needs to be meant in order to be epistemologically understood, yet their axiological quality can already be perceived in intuition (e.g., the essence of the beloved person as a positive value). Axiological properties relate to the content object in the same way as logical properties do. Yet, in general, while logical properties are necessary for the content to preserve its objectual unity, sameness, and ontological identity, axiological properties are the existential light that brings this sameness as a meaning that exists for that person.

I think that the magnitude of the disruption occurring in BPD/EUPDs' meaning-making process is very impairing for the process itself, especially in their emotional interaction with their interaffective lifeworld because value 
perceptions can make their interaffective lifeworld considerably smaller and nonsensical. While axiological properties usually coalesce with epistemological ones in such a way that their foundation integrates the sense of the whole in an epistemological (Maria, my sister) and ontological manner (Maria's concrete existence), in BPD/ EUPD's acts, the axiological contents are the main (often blinking) supervenience that generates a problematic continuity of the ontological matter (fullness) of the object in its epistemological meaning (abstractum/catego$\mathrm{rial} /$ logical) and in its ontological being (concretum/matter). This dynamic is such that, at any moment, the emotional content of their life can impair the continuity of the meanings and existence populating their affective lifeworld. If at any time Maria's concreteness is perceived as bad, Maria's concreteness might disappear in its meaning and being for them and what Maria meant for them until that moment would no longer be there for them ${ }^{20}$ (unless Maria and her father will come back after the crisis and will try again to interact and resonate with them). There is no life that can come to existence when the axiological quality of the acts does not "see" the being as a meaning and as a unit of existence for them.

\section{Coming Back to the Logics}

From this perspective, Mancini and Stanghellini's [11] description of BPD/EUPDs' logics depict the most rational answers that can be given to a reality that could drastically change at any moment. (1) The logic of intimacy whose main value is belongingness and mutual recognition is a rational answer to the deep-rooted form of existential loneliness that BPD/EUPDs might experience when the emotional disturbance occurs; (2) the logic of spontaneity whose value is authenticity is a consequential answer to an affective identity whose sameness is continuously shattered according to the axiological perception of the concreteness of life; (3) the logic of instantaneity whose guiding value is intensity is, of course, a rational way to keep together a lifeworld that is continuously disturbed in its affective and accordingly existential continuity. Rumination is another logical coping strategy to hold on to a reality that could be completely different just a few minutes later. By going over and over the same thought one can have the illusion to belong to and to be part of the world for as long as the thought is there (although the value attributed to that portion of the

20 Husserl also refers to it as a Gutwert (good-value or "goodness") that we primitively recognize as a value, and which originally comes into being as a temporal unit [66].

Meaning-Making Activity in the Emotional Experience of Borderline Personalities world is saying otherwise). Living in this way, of course, involves visible distress, disorienting feelings, and frustration.

\section{Conclusion: A Potential Treatment}

To use Scheler's interpretation of this expression, this can be identified as an ordo amoris disorder where BPD/ EUPDs' value perception originates a sense of reality that is discontinuous from an interaffective and existential point of view. The mereological foundation of meaning in BPD/EUPDs can suffer from an existential intersubjective and interaffective defect. Axiological qualities determining the matter of a certain content have the power to cloud the existence of what is there for their interaffective lifeworld, thus generating relevant emotional disturbances. From a therapeutic perspective, it can be helpful to transform invalidations in a resting moment of suspension and attenuate their existential intersubjective tone (which can be expressed in the sentence "you've never been there for me") while insisting on the affective continuity. Metaphorically speaking, the goal is to make the disturbed sound of this radio clearer and, when possible, even enjoyable.

The treatments that today are provided to heal the emotional dysregulation proper to this disorder are often based on CBT and mindfulness- and acceptance-based exercises [37]. According to Evans et al. [38], these activities are often very tiring and do not win over the forms of self-medications with which BPD/EUPDs engage to ease the pain. Yet, when well-practiced, they may reduce distress tolerance due to fatigue and self-regulatory deficits [38]. Maladaptive strategies such as avoidance, suppression, and substance abuse are more appealing at the beginning when cognitive and mindful exercises result still too challenging. If the practices of this former is prolonged, it can easily lead to greater psychopathology overall [39]. Refining the skills with which BPD/EUPDs' affective necessity brings axiological contents to meaning can be beneficial to regain a space of belongingness to the intersubjective society and to readjust the affective resonance before lacking.

I think it can be very productive to apply the results of the mereological investigation conducted above on the understanding of this specific meaning-making process. I believe that the disturbance in the affective resonance characterizing this disorder can be greatly attenuated if due attention would be paid to the axiological instantiation in the meaning content of the lived experience. In 
sum, I believe that it would be helpful if the clinicians would focus on healing the existential and interaffective blindness with which the content of experience is brought to existence in BPD/EUPDs' case. Insisting on the continuity of the reality independently of the emotional and originally axiological disruption caused by the value assigned to the concreteness of a certain lived experience can contribute to the stability of their interaffective and intersubjective world, hence increasing their sense of belongingness.

The instability that characterizes BPD/EUPDs' behavior simply mirrors the instability of their lifeworld. I think that paying attention to the existential outcome of the axiological instantiation in the meaning-making experience of BPD/EUPD is crucial to prevent that the affective resonance that connects these individuals to their intersubjective and interaffective world is not disrupted. To my knowledge, this co-foundational component of meaning has not been sufficiently emphasized in the current literature and certainly deserves more attention.

\section{Acknowledgements}

I would like to thank my colleagues, Merel Visse, Valeria Bizzari, and Richard Morehouse, and the two anonymous reviewers for their useful suggestions on this article.

\section{Conflict of Interest Statement}

The author has no conflicts of interest to declare.

\section{Funding Sources}

The author did not receive any funding.

\section{References}

1 Scheler M. Ordo Amoris. Iannascoli, L. (trans.). Rome: Aracne Editrice; 2010.

2 American Psychiatric Association. Diagnostic and statistical manual of mental disorders. 5th ed. Arlington, VA: American Psychiatric Publishing; 2013.

3 Bagge CL, Stepp SD, Trull TJ. Borderline personality disorder features and utilization of treatment over two years. J Personal Disord. 2015;19:420-39.

4 Comtois KA, Russo J, Snowden M, Srebnik D, Ries R, Roy-Byrne P. Factors associated with high use of public mental health services by persons with borderline personality disorder. Psychiatr Serv. 2003;54(8):1149-54.

5 Van Asselt AD, Dirksen CD, Arntz A, Severens JL. The cost of borderline personality disorder: Societal cost of illness in BPD-patients. Eur Psychiatry. 2007;22(6):354-61.

6 Dixon-Gordon KL, Weiss NH, Tull MT, DiLillo D, Messman-Moore T, Gratz KL. Characterizing emotional dysfunction in borderline personality, major depression, and their co-occurrence. Compr Psychiatry. 2015;62: 187-203.

7 Hughes AE, Crowell SE, Uyeji L, Coan JA. A developmental neuroscience of borderline pathology: emotion dysregulation and social baseline theory. J Abnorm Child Psychol. 2012;40(1):21-33.

8 Ratcliffe MJ, Bortolan A. Emotion regulation in a disordered world: understanding borderline personality disorder. In: Stanghellini G, Tewes C, editors. Time and body: phenomenological and psychopathological approaches. Cambridge: Cambridge University Press; 2020. p. 1-25.
9 Schmidt P. Nobody? Disturbed self-experience in BPD and four kinds of instabilities. In: Stanghellini G, Tewes C, editors. Time and body: phenomenological and psychopathological approaches. Cambridge: Cambridge University Press; 2020. p. 206-29.

10 Broome MR, Bortolotti L. Affective instability and paranoia. Discipline Filosofiche. 2018; 28(2):123-36.

11 Mancini M, Stanghellini G. Values in persons with borderline personality disorder: their relevance for the therapeutic interview. Res Psychother. 2020;23(1):449.

12 Trull TJ, Solhan MB, Tragesser SL, Jahng S, Wood PK, Piasecki TM, et al. Affective instability: measuring a core feature of borderline personality disorder with ecological momentary assessment. J Abnorm Psychol. 2018;117:647-61.

13 Fertuck EA, Lenzenweger MF, Clarkin JF, Hoermann S, Stanley B. Executive neurocognition, memory systems, and borderline personality disorder. Clin Psychol Rev. 2006; 26(3):346-75.

14 Lenzenweger MF, Clarkin JF, Fertuck EA, Kernberg OF. Executive neurocognitive functioning and neurobehavioral systems indicators in borderline personality disorder: a preliminary study. J Pers Disord. 2004;18(5):421-38.

15 LeGris J, Toplak M, Links PS. Affective decision making in women with borderline personality disorder. J Pers Disord. 2014;28:1-22.

16 Van Reekum R, Links PS, Fedorov C. Impulsivity in borderline personality disorder. In: Silk $\mathrm{KR}$, editors. Biological and neurobehavioral studies of borderline personality disorder. American Psychiatric Association; 1994. p. 1-22.
17 Sánchez-Navarro JP, Weller J, López-Navarro JM, Martínez-Selva JM, Bechara A. Suboptimal decision making in borderline personality disorder: effect of potential losses. Span J Psychol. 2014;17:1-9.

18 Gratz KL, Tull MT, Matusiewicz AM, Breetz AA, Lejuez CW. Multimodal examination of emotion regulation difficulties as a function of co-occurring avoidant personality disorder among women with borderline personality disorder. Personal Disorders. 2013;4(4):304-14.

19 Kuo JR, Linehan MM. Disentangling emotion processes in borderline personality disorder: physiological and self-reported assessment of biological vulnerability, baseline intensity, and reactivity to emotionally evocative stimuli. J Abnorm Psychol. 2009;118(3):531-44.

20 Minzenberg MJ, Fan J, New AS, Tang CY, Siever LJ. Fronto-limbic dysfunction in response to facial emotion in borderline personality disorder: an event-related fMRI study. Psychiatry Res. 2007;155(3):231-43.

21 Shenk CE, Fruzzetti AE. The impact of validating and invalidating responses on emotional reactivity. J Soc Clin Psychol. 2011; 30(2):163-83.

22 Shenk CE, Fruzzetti AE. Parental validating and invalidating responses and adolescent psychological functioning: an observational study. Fam J. 2014;22:43-8.

23 Gardner KJ, Qualter P, Tremblay R. Emotional functioning of individuals with borderline personality traits in a nonclinical population. Psychiatry Res. 2010;176(2-3):208-12.

24 Staebler K, Helbing E, Rosenbach C, Renneberg B. Rejection sensitivity and borderline personality disorder. Clin Psychol Psychother. 2011 Jul-Aug;18(4):275-83. 
25 Peters JR, Smart LM, Baer RA. Dysfunctional responses to emotion mediate the cross-sectional relationship between rejection sensitivity and borderline personality features. J Personal Disorders. 2015;29(2):231-40.

26 Selby EA, Anestis MD, Bender TW, Joiner TE. An exploration of the emotional cascade model in borderline personality disorder. J Abnorm Psychol. 2009;118(2):375-87.

27 Berenson KR, Downey G, Rafaeli E, Coifman KG, Paquin NL. The rejection-rage contingency in borderline personality disorder. J Abnorm Psychol. 2011;120(3):681-90.

28 Peters JR, Geiger PJ, Smart LM, Baer RA. Shame and borderline personality features: The potential mediating role of anger and anger rumination. Personal Disord. 2014;5(1): $1-9$.

29 Selby EA, Fehling KB, Panza EA, Kranzler A. Rumination, mindfulness, and borderline personality disorder symptoms. Mindfulness. 2015;7(1):228-35.

30 Gottman JM. A theory of marital dissolution and stability. J Family Psychol. 1993;7(1):5775.

31 Dixon-Gordon KL, Peters JR, Fertuck EA, Yen S. Emotional processes in borderline personality disorder: an update for clinical practice. J Psychother Integr. 2017;27(4):425-38.

32 Spiegel D, Lulu J, Willson S. Dissociative amnesia. Merck manual, professional version. Kenilworth, NJ: Merck, Sharp \& Dohme Corp; 2017.

33 Husserl E In: Claesges U, editor. Ding und Raum: Vorlesungen 1907 Husserliana Edmund Husserl Gesammelte Werke. Den Haag: Martinus Nijhoff; 1973.

34 Husserl E In: Panzer U, editor. Logische untersuchungen. Den Haag: Martinus Nijhoff; 1984.

35 Husserl E In: Jacobs H, editor. Einleitung in die Philosophie. Vorlesungen 1916-1920. Dordrecht, Heidelberg, New York and London: Springer; 2012.

36 Staiti A. Etica naturalistica e fenomenologia. Firenze: Mulino; 2019.

37 McMain S, Links PS, Guimond T, Wnuk S, Eynan R, Bergmans Y, et al. An exploratory study of the relationship between changes in emotion and cognitive processes and treatment outcome in borderline personality disorder. Psychother Res. 2013;23(6):658-73.
38 Evans DR, Eisenlohr-Moul TA, Button DF, Baer RA, Segerstrom SC. Self-regulatory deficits associated with unpracticed mindfulness strategies for coping with acute pain. J Appl Soc Psychol. 2014;44(1):23-30.

39 Aldao A, Nolen-Hoeksema S, Schweizer S. Emotion-regulation strategies across psychopathology: a meta-analytic review. Clin Psychol Rev. 2010;30(2):217-37.

40 Decety J. Dissecting the neural mechanisms mediating empathy. Emotion Rev. 2011;3(1): 92-108.

41 Decety J, Cowell JM. The complex relation between morality and empathy. Trends Cogn Sci. 2014;18(7):337-9.

42 Fuchs T. Corporealized and disembodied minds: a phenomenological view of the body in melancholia and schizophrenia. Philos Psychiatr Psychol. 2005;12(2):95-107.

43 de Haan S. The existential dimension in psychiatry: an enactive framework. Ment Health Relig Cult. 2017;20(6):528-35.

44 de Haan S. Enactive psychiatry. 1st ed. Cambridge: Cambridge University Press; 2020.

45 García-Mieres H, Niño-Robles N, Ochoa S, Feixas G. Exploring identity and personal meanings in psychosis using the repertory grid technique: a systematic review. Clin Psychol Psychother. 2019;26(6):717-33.

46 George LS, Park CL. Meaning in life as comprehension, purpose, and mattering: toward integration and new research questions. Rev Gen Psychol. 2016;20(3):205-20.

47 Heine SJ, Proulx T, Vohs KD. The meaning maintenance model: on the coherence of social motivations. Pers Soc Psychol Rev. 2006; 10(2):88-110

48 Heintzelman SJ, King LA. On knowing more than we can tell: intuitive processes and the experience of meaning. J Positive Psychol. 2013;8(6):471-82.

49 Heintzelman SJ, King LA. Life is pretty meaningful. Am Psychol. 2014;69(6):561-74.

50 King LA, Heintzelman SJ, Ward SJ. Beyond the search for meaning: a contemporary science of the experience of meaning in life. Curr Dir Psychol Sci. 2016;25(4):211-6.

51 Larsen JA. Finding meaning in first episode psychosis: experience, agency, and the cultural repertoire. Med Anthropol Q. 2004;18(4): $447-71$.

52 Martela F, Steger MF. The three meanings of meaning in life: distinguishing coherence, purpose, and significance. J Positive Psychol. 2016;11(5):531-45.
53 Park CL, George LS. Assessing meaning and meaning making in the context of stressful life events: measurement tools and approaches. J Positive Psychol. 2013;8(6):483-504.

54 Proulx T, Inzlicht $M$. The five "A"s of meaning maintenance: finding meaning in the theories of sense-making. Psychol Inq. 2012; 23(4):317-35.

55 Park CL. Testing the meaning making model of coping with loss. J Soc Clin Psychol. 2008;27(9):970-994.

56 Sass L, Pienkos E. Varieties of self-experience: a comparative phenomenology of melancholia, mania, and schizophrenia, part I. J Conscious Stud. 2013;20(7-8):103-30.

57 Stanghellini G, Bolton D, Fulford WKM. Person-centered psychopathology of schizophrenia: building on Karl Jaspers' understanding of patient's attitude toward his illness. Schizophr Bull. 2013;39(2):287-94.

58 Stanghellini G, Rosfort R. Disordered selves or persons with schizophrenia? Curr Opin Psychiatry. 2015;28(3):256-63.

59 Suri R. Making sense of voices: an exploration of meaningfulness in auditory hallucinations in schizophrenia. J Humanistic Psychol. 2011; 51(2):152-71.

60 Thomas JL. Meaningfulness as sensefulness. Philosophia; 2019.

61 Fuchs T, Koch SC. Embodied affectivity: on moving and being moved. Front Psychol. 2014;5:508.

62 Pallaro P. Somatic countertransference: the therapist in relationship. In: Pallaro P, editor. Authentic movement: moving the body, moving the self, being moved. London: Jessica Kingsley Publisher; 2006. p. 80-95.

63 Husserl E In: Carr D, editor. Crisis of European Science. Evanston: Northwestern University Press; 1970.

64 Ferrarello $S$. The role of bioethics in emotional problems. London: Routledge; 2021.

65 Leśniewski S. Foundations of the general theory of sets. In: Surma SJ, editor. Barnett SI, translator. Stanislaw Leśniewski: collected works. Dordrecht: Kluwer; 1992. Vol. 1. p. 129-73.

66 Fuchs T. Self across time: the diachronic unity of bodily existence. Phenomenol Cogn Sci. 2017;9:429-52.

67 Fuchs T. The ecology of the brain. Oxford: Oxford University Press; 2017.
Meaning-Making Activity in the Emotional Experience of Borderline Personalities
Psychopathology 2021;54:221-231 